Est Ag 54 (2019) 109-140

\title{
La utilización de san Pablo en los In Epistulam Iohannis ad Parthos Tractatus de san Agustín (II)
}

\author{
Pío DE LuIS ViZCAÍNO
}

Resumen: Es bien sabido que san Juan y san Pablo son los dos autores del Nuevo Testamento preferidos por el obispo de Hipona si la preferencia se mide por la dedicación a sus escritos y por el recurso a los mismos. Pero, de los dos hagiógrafos ¿cuál ha tenido más peso en el pensamiento del santo? ¿Cuál ocupa el primer lugar? Leídos desde esa perspectiva sus Tractatus sobre la carta de san Juan a los Partos $\left(=1^{\text {a }}\right.$ de Juan), no cabe sino responder que el Apóstol ha ganado la partida al evangelista. En el presente estudio se examinan, primero, diversos aspectos del uso del Apóstol en los Tractatus (frecuencia, modos de designación, la técnica de la cita, funciones sintácticas de la cita...) y, después, los variados objetivos que cumplen los textos de san Pablo en el comentario a la carta juánica (confirmación, complemento, solución de cuestiones, desarrollo de temas paralelos, comprensión de otros textos bíblicos, polémica, etc.). El análisis de los textos revela cómo el predicador da la preferencia a san Pablo antes que a san Juan; cómo la teología paulina se sobrepone a la juánica; cómo el santo no desaprovecha ningún recurso para dar el salto de san Juan a san Pablo. San Pablo parece ser para san Agustín, de facto, un buen intérprete de san Juan. Cosa distinta es que la realidad se ajuste a lo que piensa el obispo de Hipona.

Palabras clave: Tratados sobre la primera carta de san Juan; técnica de la cita; función de la cita; teología paulina.

Abstract: It is well known that St. John and St. Paul are the two authors of the New Testament preferred by the bishop of Hippo, if preference is measured by dedication to his writings and recourse to them. However, of the 
two hagiographers who exerts more weight in the saint's thought? Which one occupies the first place? Read from this perspective his Treatise on the letter of St. John to the Parthians (1 John), the answer is clear: The Apostle has won the game to the evangelist. The present study examines, first various aspects of the use of the Apostle in the Treatise (his frequency, modes of quotation, technique of quotation, syntactic functions of the quotation...) and, then, the various objectives the texts of Saint Paul fulfil in the commentary on the Johannine letter (confirmation, addition, solution of questions, development of parallel themes, understanding of other biblical texts, controversy, etc.). The analysis of the texts reveals how the preacher prefers Saint Paul to Saint John; how Pauline theology overcomes the Johannine; how the saint does not waste any resources to make the leap from Saint John to Saint Paul. Saint Paul seems to be for Saint Augustine, de facto, a good interpreter of Saint John. Distinct however is if what the Bishop of Hippo thinks is consistent with the truth.

Keywords: Treaties on the first letter of Saint John; technique of quotation; function of quotation; Pauline theology.

\section{Visión global}

Concluido el análisis de los textos ${ }^{1}$, es el momento de hacer una presentación más sistemática.

\section{Presencia de san Pablo}

En relación con la presencia de san Pablo en los Tractatus agustinianos sobre la primera carta de san Juan cabe destacar dos datos: a) el amplio uso que el predicador de Hipona hace de sus textos; b) la variedad de formas en que los utiliza o, si se prefiere, la variedad de funciones que los textos paulinos asumen en el texto agustiniano.

a) Amplio uso

El casi centenar de presencias - entre citas textuales, referencias o simples alusiones- en un conjunto de diez homilías es significativo. Representa

\footnotetext{
${ }^{1}$ La primera parte de este estudio la puede hallar el lector en Estudio Agustiniano 53 (2018) 149-239. Como en él, seguimos utilizado la abreviatura IIEp (in Ioannis epistulam).
} 
una media de 10 empleos en cada Tractatus. De este amplio uso puede aducirse como razón la extensión del epistolario paulino, pero no lo explica todo ${ }^{2}$. Es más lógico atribuirlo a otras causas: la vinculación existencial del pastor de Hipona con el apóstol Pablo, el más profundo conocimiento que tenía de él que de san Juan, la historia personal de Pablo.

Dos acontecimientos fundamentales en la trayectoria cristiana de san Agustín estuvieron marcados por san Pablo: el de su conversión y el de su ordenación presbiteral. El primero de ellos tuvo lugar, como es bien sabido, tras la lectura de un texto de la Carta a los Romanos (Rom 13,13-14); en el segundo, el Apóstol le suministró las claves para el ejercicio del ministerio que le acababa de ser conferido ${ }^{3}$. Su retorno a la fe de la Iglesia y su condición de pastor en ella estuvieron profundamente vinculados al Apóstol. En cambio, nada igual, y ni siquiera similar, puede afirmarse en relación con san Juan.

Como consecuencia de lo dicho, amén de otros condicionantes histó$\operatorname{ricos}^{4}$, san Agustín, que ya había leído atentamente a san Pablo antes de su conversión (cf. conf. 7,21,27), una vez ordenado presbítero volvió a él con mayor intensidad a nivel particular y en compañía de otros siervos de Dios. El trato continuo con el Apóstol le proporcionó un conocimiento extraordinario de sus cartas que acabó impregnando en cuanto a ideas y vocabulario la propia obra del obispo. De ese conocimiento salieron sus primeros comentarios, parciales, sobre la Carta a los Romanos y uno completo sobre la Carta a los Gálatas. Nada similar puede decirse, en cambio, en relación con san Juan. Su trato con este apóstol fue mucho menos intenso y solo quince años después de su ordenación presbiteral, en el 406, se atrevió a iniciar la exposición de su evangelio que, como indicamos, hubo de interrumpir y dejó el espacio para la exposición de su primera carta.

Por último, los escritos juánicos aportan pocos datos sobre la vida de su autor; en cambio san Pablo dejó en sus cartas un vivo retrato de sí mismo, de su pasado y de su presente, de sus ideas y de sus motivaciones. San Agustín, que se presenta a sí mismo como expositor de san Juan y como imita-

${ }^{2}$ De hecho, aun siendo bastante mayor la extensión del conjunto de los cuatro evangelios, su presencia en forma de citas es solo ligeramente superior a la de las cartas paulinas.

${ }^{3}$ Cf. Luis Vizcaíno, P. de, "El encuentro de san Agustín con san Pablo", en Vicente Domingo Canet Vayá (ed.), San Pablo en San Agustín. XII Jornadas Agustinianas. Centro Teológico San Agustín, Madrid 2009, 28-36.

${ }^{4}$ Nos referimos a la pertenencia de san Agustín al maniqueísmo. Cf. Ibíd., 27-28. 
dor de san Pablo (IIEp 9,1), encontraba en él un maestro y un modelo de vida tanto para sí -en el plano puramente personal y en su condición de pastor-como para el conjunto de los fieles. En cambio, a san Juan lo podía considerar, sí, como el gran maestro que bebió en el pecho del Señor (cf. Jn $13,25)$, pero apenas podía encontrar en él un modelo de acción y de vida que proponerse a sí mismo y a su comunidad eclesial. En otros términos, contaba con el magisterio de su palabra pero apenas con el de su vida.

Estos tres datos pueden explicar el amplio uso de san Pablo en sus Tractatus, pero no puede explicar todavía la querencia que san Agustín manifiesta hacia él.

\section{b) Variedad de funciones}

Las citas paulinas los Tractatus cumplen efectivamente varias funciones. Hablamos en general de los Tractatus porque el recurso a san Pablo en ellos no guarda relación solo con el texto de san Juan. De hecho, no siempre los textos paulinos son solicitados por textos de la Carta apostólica; no pocos de ellos aparecen en relación con otros textos bíblicos, sea porque san Agustín los ha buscado para su exposición del texto de la Carta, sea porque habían sido objeto de lectura en la liturgia eucarística del día, sea porque san Agustín los ha traído a colación como confirmación o prueba de alguna idea particular suya. Incluso hay textos paulinos introducidos por el predicador y puestos directamente al servicio de sus propios planteamientos, hasta el punto, por ejemplo, de invertir los términos y utilizar a san Juan para exponer la teología paulina.

Vengamos ya a los textos paulinos, solicitados por otros textos juánicos, que representan una clara mayoría. En la perspectiva del predicador, el texto juánico -o su interpretación por parte del obispo-necesita ser confirmado, o ser complementado para su mejor intelección, o suscita cuestiones que requieren ser resueltas, o sugiere temas que despiertan el interés del predicador, o admite una interpretación polémica contra los herejes o cismáticos. En todas estas situaciones el predicador de Hipona ha recurrido a san Pablo, encontrando siempre luz, la adecuada a cada caso. El epistolario paulino era como el almacén donde él encontraba siempre el material que necesitaba. De hecho, en san Pablo no buscaba solo la enseñanza sino también el ejemplo, pues, para el predicador, san Pablo fue el fiel cumplidor de lo que prescribe el evangelio (cf. IIEp 8,2). 


\section{Querencia por san Pablo}

El epígrafe puede resultar extraño. Habida cuenta de que nos ocupamos precisamente de la exposición de la primera Carta de san Juan, cabría esperar que el epígrafe fuera «Querencia por san Juan». Pero en los Tractatus es fácil advertir una inclinación o tendencia del obispo de Hipona a volver al «espacio» en que se crió como cristiano católico, el apóstol Pablo, como si solo allí se sintiera verdaderamente a gusto. Un menú puede ser realmente exquisito, pero no se siente tan sabroso como el preparado por la madre. Es solo una imagen de una realidad que a continuación vamos a justificar con ejemplos concretos.

Como prueba de esa querencia está el hecho de que san Pablo parece ser para él la autoridad de referencia. Es frecuente encontrar en él la pregunta «¿qué dice (el apóstol Pablo)?» cuando pretende mostrar o probar algo (IIEp 1,$\left.10 ; 2,4 ; 3,4 ; 5,4 ; 8,2^{5}\right)$. A veces parece no bastarle la afirmación explícita de san Juan sobre algo. Como si para él no tuviera suficiente peso de autoridad su palabra, busca la confirmación definitiva de la propia propuesta en la autoridad de san Pablo; requiere que la afirmación sea avalada por él (IIEp 4,5;1,5;1,10; 7,7). En algún caso sigue ese mismo proceder con el evangelista Mateo (IIEp 8,2 $)^{6}$. Es también significativo que, a la hora de exponer determinados pasajes de la carta de san Juan, deje de lado el texto juánico que acaba de citar, para el que no encuentra referente en san Pablo, y pase a comentar otro para el que sí lo encuentra ${ }^{7}$.

${ }^{5}$ La misma pregunta solo la formula una vez referida al Señor (IIEp 3,8), al salmista (Ibíd. 1,12; 9,4) y al evangelio (Ibíd. 10,10). Referida a san Juan, en su primera Carta, cf. 1,8; 4,8.12; 7,2.5. Véase también IIEp 7,7: «No lo digo yo, es el apóstol quien lo dice».

${ }^{6}$ Cf. también IIEp 1,5; 1,10; 7,7 donde entran en juego, respectivamente, 1 Jn 1,6/2 Cor 6,14c; 1 Jn 2,7 y Col 39b-10a/ Ef 5,8a-b, y 1 Jn 4,9 y Jn 15,13, Rom 8,32 y Gál 2,20e. Al contrario, en IIEp 9,4 donde después de citar Rom 5,35, aduce como complemento 1 Pe 3,13.

${ }^{7}$ En IIEp 2,6, por ejemplo, el predicador acaba de citar 1 Jn 2,13 (porque habéis vencido al Maligno) que podía haber comentado con san Juan mismo, aduciendo, por ejemplo, a Jn 16,33 (yo he vencido al mundo), o a 1 Jn 5,4 (lo que ha nacido de Dios vence al mundo y lo que vence al mundo es nuestra fe); pero como no encuentra ningún texto paulino que mencione esa victoria, da el salto a $1 \mathrm{Jn} 2,14 \mathrm{f}$ (... porque sois fuertes) para el que cuenta con 2 Cor 13,4ab que menciona la fuerza de Dios (viviremos en él por la fuerza de Dios sobre nosotros). Semejante modo de actuar se advierte también en IIEp 1,10 donde, pudiendo comentar $1 \mathrm{Jn}$ 2,7.8 (mandamiento nuevo/viejo) con Jn 13,34, opta por recurrir a Col 3,9b-10a (hombre viejo/nuevo). 
La misma conclusión se puede sacar del método de la inclusión que utiliza un par de veces. El santo se encuentra con dos versículos seguidos de la Carta de san Juan, viendo en el segundo la explicación del primero. En teoría, para hacer inteligible el primero debería bastarle exponer el segundo. Pero el santo parece necesitar recurrir a Pablo y entre el primer y el segundo versículo de san Juan introduce una serie de textos paulinos que, según él, dicen lo mismo que el segundo, esto es: Juan 1 + larga exposición de Pablo + simple mención de Juan 2. Lo más apreciado parece ser lo que va dentro, como en los sándwiches ${ }^{8}$.

En el mismo sentido cabe interpretar otros modos de actuar del predicador. Cuando un texto juánico contiene varios datos, el predicador se centra solo en uno y deja de lado el otro o los otros. Lo llamativo es que, en algunos casos, el elegido por el predicador es precisamente el que puede iluminar fácilmente con textos paulinos ${ }^{9}$. De modo similar, el predicador

${ }^{8}$ Los textos del primer caso, en IIEp 6,2-3 son: 1 Jn 3,18 + 1 Cor 4,3; 2 Cor 1,12,a; 1 Cor 13,3; Gál 6,4; 4,4 + 1 Jn 3,19, poniendo de relieve que los textos paulinos dicen lo mismo que 1 Jn 3,19: «Esto es lo que nos recomienda aquí el apóstol san Juan: En esto conocemos que somos de la verdad, es decir, en el hecho de amar con obras y en verdad, no solo de palabra y de boca, y persuadimos a nuestro corazón en su presencia (1 Jn 3,19)». Los del segundo caso, en IIEp 4,11, son estos otros: 1 Jn 3,8c + Rom 5 + 1 Jn 3,18d. En principio, dada la cercanía entre 1 Jn 2,14h (habéis vencido al maligno) y 1 Jn 2,16 (las tres concupiscencias) podía haber considerado estas como las obras del diablo, pero optó por apartarse del plural juánico para quedarse con el singular «paulino» (el pecado original). Más adelante, en IIEp 5,2 Agustín mantendrá el plural, pero sin explicitarlo.

${ }^{9}$ Según san Juan, Dios manifiesta su amor por el hombre enviando a su Hijo a este mundo (1 Jn 4,9b) y enviándolo como expiación de los pecados del hombre (1 Jn 4,10d). Ahora bien, en IIEp 7,7 san Agustín renuncia a comentar la primera manifestación del amor divino de que habla san Juan (la encarnación -de poca o nula relevancia en san Pablo-) y se centra en la segunda, la muerte de Cristo; además, con relación a esta segunda, prefiere aducir dos textos paulinos -Rom 8,32 y Gál 2,20- antes que detenerse, por ejemplo, en 1 Jn 4,10 (nos envió a su Hijo como propiciación por nuestros pecados). A los dos envíos de san Juan (encarnación, y pasión y muerte), el predicador responde con las dos entregas a la muerte de que habla san Pablo: la realizada por el Padre y la realizada por Cristo mismo. Un caso similar lo encontramos en IIEp 9,9. En 1 Jn 4,19, san Juan invita a sus lectores a amar a Dios porque él los amó primero. Lo más probable es que el apóstol esté pensando en la encarnación (cf. 1 Jn 4,14: damos testimonio de que el Padre envió a su Hijo como salvador del mundo). No obstante, san Agustín deja al margen este primer dato cristológico, aunque contaba con otros textos juánicos de apoyo (p. ej. Jn 3,16), y asocia al texto juánico el paulino de Rom 5,8 que prueba el amor de Dios por nosotros por el hecho de que Cristo murió por nosotros cuando aún éramos pecadores. 
pasa por alto lo que literalmente afirma el texto de san Juan y se centra en otro concepto paulino, aunque íntimamente relacionado con é ${ }^{10}$. Por último, sorprende que, enfrentado a dos textos, uno de Juan y otro de Pablo que tratan de la misma realidad pero presentando el primero un dato teológico y el segundo un dato moral, se detenga, contra lo que es su modo habitual de proceder, en el segundo y no en el primero ${ }^{11}$.

Del modo de actuar señalado se pueden extraer dos conclusiones que se complementan. Una, que san Agustín tiene una querencia particular por san Pablo que le lleva dar luego el salto de un texto juánico a uno paulino; otra, que conoce mejor a san Pablo que a san Juan, lo que explicaría en parte ese modo de actuar. No hay que olvidar que se trata de un texto de predicación y que las otras citas bíblicas a que recurre para el comentario las suministra la memoria ${ }^{12}$.

\section{El grammaticus teólogo y pastor}

La interpretación agustiniana sigue tres cauces; uno de naturaleza gramatical, otro de naturaleza teológica y otro de naturaleza pastoral ${ }^{13}$, íntimamente relacionados.

\section{a) El grammaticus}

En su época de estudiante, san Agustín hubo de seguir los cursos del grammaticus; luego, durante algún tiempo, ejerció él mismo como tal. El

${ }^{10}$ Así en IIEp 8,13, a propósito de 1 Jn 4,14. En vez de presentar a Jesucristo como salvador de quien habla el texto, prefiere ocuparse, sirviéndose, por supuesto, de textos paulinos, de una salvación -concepto abstracto que no está en 1 Jn, aunque sí en Jn 4,22- en dos etapas: una en esperanza (Rom 8,24) y otra escatológica (1 Cor 15,53-54). El desplazamiento resulta doble: del salvador a la salvación y del salvador al salvado.

${ }^{11}$ En IIEp 4,7 asocia 1 Jn 3,3 que habla de la esperanza en Cristo y Rom 8,24-25 que vincula la esperanza con la paciencia. Lo que llama la atención es que se detenga en el aspecto moral presente en Pablo («con paciencia») y no en el aspecto teológico afirmado por Juan («en él», en Cristo).

${ }^{12}$ Agustín solía predicar sentado teniendo en sus manos el códice del libro de la Escritura que estaba comentando (s. 37,1,1).

${ }^{13} \mathrm{Al}$ hablar aquí de naturaleza pastoral consideramos solo lo relacionado con la existencia de la comunidad cismática donatista. 
grammaticus enseñaba la lectura e interpretación de los textos. Su campo de trabajo lo constituían las palabras: sus variadas formas, sus complejas conexiones, sus matizados significados tal como se encontraban en los textos de los autores más cualificados de la tradición literaria latina. A resultas de ello, san Agustín fue siempre alguien que amó y valoró la palabra y que reflexionó sobre ella en sus diversos aspectos. Hasta cabe explicar su afinidad con san Juan por el hecho de ser el evangelista de la Palabra.

Convertido en ministro de la Iglesia, en su incesante tarea de comentar esa Palabra no solo tuvo la ayuda inestimable de la antigua profesión sino, quizá, hasta la sensación de volver a ella. El texto que en determinado momento expuso a sus oyentes fue la primera Carta de san Juan. Limitándonos siempre a las partes en que hace recurso al apóstol san Pablo, esa condición de grammaticus se manifiesta, por ejemplo, en el explicar el sentido propio de ciertas palabras (IIEp 4,4: «llamarse» $\mathrm{y}$ «ser»; 4,5: «es»; 8,2: Paulo; 8,5: dilectio y amor; 10,5: «fin»); en el aferrarse al tenor literal del texto (IIEP 1,8.9; 2,5; 3,6; 5,1.2: no dijo «esto», sino «aquello»); en la atención prestada a los tiempos de los verbos (IIEp 5,1): no dice «tuvimos», sino «tenemos»); en el advertir un solecismo (IIEp 10,3: paso del singular «engendrado» al plural «hijos» en 1 Jn 5,1-2); en el indicar el alcance de una partícula comparativa (IIEp 4,9; 5,2; 9,3: en relación con el uso de la conjunción «como»). Se advierte también la presencia del grammaticus cuando asume el valor afirmativo de una pregunta retórica (Rom 8,35, en IIEp 9,4); cuando advierte identidad semántica bajo expresiones diversas (entre $1 \mathrm{Jn}$ 4,17 y Fil 1,23b-24, en IIEp 9,2); cuando advierte el empleo de un lenguaje metafórico; cuando muestra saber deducir una cosa de otra (IIEp 5,714); cuando recurre al contraste para asociar textos (IIEp 2,1: dureza/dulzura); cuando trasciende el hecho concreto y busca la causa (IIEp 5,8); cuando acude incluso a la filosofía (IIEp 9,9: belleza y amor); cuando utiliza a san Pablo como ejemplo para explicar lo dicho por san Juan (IIEp 6,4-7); y, en general, cuando, en sus diferentes formas, explica o complementa lo dicho por san Juan con textos de san Pablo.

La pregunta que ahora cabe formularse es si, de hecho, san Agustín actúa conforme a la ortodoxia del grammaticus en el caso concreto que nos

\footnotetext{
${ }^{14}$ Semilla es la palabra de Dios: lógicamente el texto no afirma directamente eso, pero permite deducirlo. Si Pablo engendra para Dios por la predicación del evangelio, es decir de la palabra de Dios, resulta claro que la semilla es la palabra de Dios.
} 
ocupa. La pregunta está justificada por una serie de datos tomados de los tractatus. Entre otros, anotamos los siguientes, referidos siempre al uso que hace de los textos de san Juan y de san Pablo: el predicador de Hipona no advierte el significado específico que uno y otro apóstol asigna a determinados conceptos ${ }^{15}$ (IIEp 1,6:1 Jn 1,10/Rom 3,4: verdad), o el significado diverso de conceptos formalmente sinónimos ${ }^{16}$; o no presta atención al tiempo de los verbos, al sujeto u objeto de una acción ${ }^{17}$, a la naturaleza de un genitivo -si tiene valor objetivo o subjetivo (Rom 8,35)-, a las diferentes preposiciones que acompañan a un nombre, al significado preciso que se oculta bajo el lenguaje metafórico, a los diferentes momentos cronológicos de determinados hechos, a las diferentes categorías filosóficas (efecto/causa), a los distintos ámbitos (moral/antropología ${ }^{18}$; físico/metafí$\operatorname{sico}^{19}$ ), a las distintas funciones ${ }^{20}$, a las diferentes conclusiones extraídas de una misma realidad ${ }^{21}$; no considera el texto en su totalidad sino que selecciona en Juan para contar con Pablo 22 ; plantea las cuestiones de modo que faciliten introducir el texto paulino en que está pensando ${ }^{23}$; privilegia aquellos aspectos del texto de Juan que puede comentar con un pasaje paulino ${ }^{24}$; une donde san Juan separa.

Los puntos señalados recogen el grueso de las observaciones hechas a la interpretación de san Juan con textos de san Pablo. Pero todas ellas se

${ }^{15}$ Es el caso de los «niños» de 1 Jn 2,18a y 1 Cor 3,2 en IIEp 3,1; de la «justicia de 1 Jn 2,29 y de Rom 1,17, en IIEp 4,3; las categorías de «nuevo y viejo» de 1 Jn 2,7 y de Col 3,9b10a en IIEp 1,10.

${ }^{16}$ Por ejemplo, los conceptos «precepto», «mandamiento», «ley».

${ }^{17}$ Por ejemplo, del amor o del temor.

${ }^{18}$ Así las tinieblas de 1 Jn 2,8 y las de Ef 5,8 en IIEp 1,10 (cosmología espiritual/antropología); IIEp 1,10:1 Jn 2,7/Gal 3,9b-10ª (moral/antropogía).

${ }^{19}$ Así mientras san Juan habla de un permanecer (habitar en un lugar) en 1 Jn 4,16b, Agustín pasa a una permanencia en el ser (no decaer) en 1 Cor 13,8a.

${ }^{20}$ Así al Espíritu de 1 Jn 3,24 y Rom 5,5b en IIEp 6,9; o al de 1 Jn 4,12-13 y Rom 5,5,b, en IIEp 8,12.

${ }^{21}$ Así de 1 Jn 4,9 y de Rm 5,8, en IIEp 9.9.

${ }^{22}$ Así 1 Jn 3,10 y Rom 13,8b.10b, en IIEp 5,7; o 1 Jn 5,1 y Gal 5,6 en IIEp 10,2; 1 Jn 4,18 y Rom 8,35 en IIEp 9,4.

${ }^{23}$ Así en $1 \mathrm{Jn}$ 5,1ab en vez de preguntarse quién es el que cree, se pregunta quién no cree (1 Jn 5,1ab/Gal 5,6c, en IIEP 10,1).

${ }^{24}$ En 1 Jn 3,2 san Juan señala dos datos de la escatología: el cristiano será semejante a Dios y le verá tal cual es. El santo se fija solo en el segundo, que puede asociar con el deseo paulino de estar junto a Dios (Fil 3,13-14) (IIEp 4,6). 
pueden resumir en una pregunta: ¿procede correctamente el grammaticus san Agustín al interpretar a un apóstol con otro?

Lo cierto es que en el texto agustiniano san Pablo es clave para interpretar a san Juan y, de otra parte, que el modo de proceder del predicador de Hipona deja la impresión de que el pensamiento de san Juan -y el de san Pablo en algunos casos-, ha sido adulterado. De hecho, el resultado del comentario agustiniano al texto de san Juan es, con frecuencia, más una comprensión de san Pablo que de san Juan mismo ${ }^{25}$; en otros casos es más provechoso para conocer lo que piensa san Agustín, inspirándose en san Pablo, que lo que dice san Juan. La teología de la encarnación de Cristo propia de san Juan queda relegada a favor de la teología paulina de la pasión, muerte y resurrección y, más en general, el texto de Juan adquiere en el comentario agustiniano un claro sesgo antropológico-soteriológico de cuño paulino ${ }^{26}$ y, en otros casos, escatológico (1 Jn 3,6). San Juan queda sometido a san Pablo (IIEp 4,11) y la teología paulina aparece, a veces, superpuesta a la de san Juan. Por otra parte, lo que en principio se presenta solo como un ejemplo que debería confirmar lo dicho por san Juan acaba convirtiéndose en la enseñanza central (oración) ${ }^{27}$. San Pablo aparece citado incluso en defensa de san Pablo mismo ${ }^{28}$. También se dan casos en que el Apóstol no es aducido para explicar a san Juan, sino la teología agustiniana. El obispo aprovecha el texto juánico para hacer llegar a sus fieles ideas que le son muy queridas, de ascendencia paulina ${ }^{29}$ : desde san Juan el lector llega a san Agustín pasando por san Pablo. No faltan casos en que el

${ }^{25}$ Así de 1 Jn 2,13-14 (conocimiento) a 1 Cor 8,1b (ciencia y caridad) en IIEp 2,8; de 1 Jn 3,2 (verle como es) a Fil 3,13-14 (deseo de estar con Cristo) en IIEp 4,6; de 1 Jn 4,7 (confianza en el juicio) a Fil 3,13-14 (deseo) en IIEp 9,2; de 1 Jn 2,18a (niños) a 1 Cor 3,2 (cristianos carnales) en IIEp 3,1.

${ }^{26}$ Es el caso en IIEp 26, en relación a 1 Jn 2,13cd y 2,14f.

${ }^{27}$ Así en IIEp 6,4-7: al final ya no se tratará tanto de que el cristiano recibirá lo que pida a Dios (1 Jn 3,21-22), sino que Dios le da lo que conviene a la salvación, no lo que se le pide.

${ }^{28}$ El texto paulino de Rom 1,24a no representa una refutación de su tesis, puesto que en este caso les faltaba la caridad. Rom 5,5b no es traído aquí para explicar a san Juan, sino a san Pablo mismo. San Agustín piensa haber salvado la verdad del texto juánico y, al mismo tiempo, defendido a san Pablo de un innominado acusador (IIEp 6,8).

${ }^{29}$ A propósito de 1 Jn 3,2, que habla de la futura visión de Dios como él es, Agustín ha introducido el tema del deseo de la vida futura -considerado como medio que agranda la capacidad humana para poder acoger lo que en esta vida resulta inaccesible para nuestros sentidos y corazón (cf. 1 Cor 2,9) - y al servicio de esa idea cita Fil 3,13-14, no sin añadir 1 Cor 2,9b-d, para señalar que lo deseado queda fuera de alcance en esta vida $(\operatorname{IIEp~} 4,6)$. 
predicador se mantiene fiel a san Juan, apartándose de san Pablo ${ }^{30}$, y otros en los que el recurso a Pablo comporta un enriquecimiento de san Juan ${ }^{31}$.

\section{b) Teólogo}

Tras lo dicho en el apartado anterior, no hay que precipitarse a emitir juicios de valor. A la hora de valorar los resultados de la exégesis agustiniana de la carta primera de san Juan -como de cualquier otro libro bíblico- hay que ser prudentes y tratar de juzgarla desde su particular circunstancia y desde sus propios criterios, y no, por ejemplo, desde los de la exégesis moderna, con la riqueza de sus medios, de naturaleza interdisciplinar, de que carecía el exégeta de Hipona.

En primer lugar, procede tener en cuenta que los tractatus son fruto de predicación, no de actividad académica; que su ubi era el templo, no el aula. En segundo lugar, no hay que olvidar que el texto sobre el que ejercía su condición de grammaticus, la primera Carta del apóstol Juan, formaba parte de la Sagrada Escritura. Eso significa que, según la fe de la Iglesia, goza de doble autoría: humana -la del hagiógrafo- y divina. Este particular hacía de san Agustín un grammaticus especial, un grammaticus teólogo. El grammaticus Agustín interpretaba la palabra de Dios, tarea del teólogo. Actuar como grammaticus equivalía a ejercer de teólogo y ejercer de teólogo requería actuar como grammaticus.

Si las palabras tienen el significado que el autor les asigna en cada caso concreto, el hecho de tener a Dios como autor ha de tener su repercusión. El hagiógrafo es un intermediario entre Dios y el fiel que lee el texto bíblico. Pero un intermediario pobre. En efecto, ¿puede el autor humano captar enteramente la semántica divina? Lo que el hagiógrafo pretende decir lo pretende decir Dios, pero no todo lo que Dios pretende decir lo dice el hagiógrafo. Desde el momento que se acepta -como era el caso de san Agustín- que cualquier sentido que no se oponga a la fe puede haber sido querido por Dios, aumenta el calibre semántico de las palabras. El hecho abre las puertas a otros modos de interpretar cualquier término o pasaje. In-

${ }^{30}$ La tinieblas son los cristianos, no los paganos (1 Jn 1,3.5.6/ 1 Cor 6.14c: IIEp 1,5).

${ }^{31}$ Así respecto de la caridad la afirmación de que la caridad no es inactiva con Heb 12,67 en IIEp 7,11; 8,11 y 8,7; de que tiene su trono en el interior del hombre con Ef 3,17, en IIEp 8,1 ; de que nunca cesará, con Heb 13,1 en IIEp 8,3; de que busca que todos sean iguales, con 1 Cor 7,7 en IIEp 8,8; de que tiene su réplica negativa en el orgullo con 1 Tim 6,10a en IIEp 8,6. 
cluso el principio -obvio- que recomienda interpretar al autor por el autor mismo, aplicado al comentario de la Escritura, adquiere otro significado. Si su autor último es Dios, es legítimo interpretar a Juan por Pablo o a Pablo por Juan o por cualquier otro autor sagrado; en última instancia, siempre se explica a Dios por Dios. Más todavía: en la eternidad de Dios los tiempos no existen: el pasado era profecía del presente y el presente, profecía del futuro.

San Agustín concebía de modo distinto que hoy la relación entre la autoría divina y la autoría humana de los libros canónicos. En todo caso, para él era fundamental la unidad de la Escritura. La imagen de las dos flautas tocadas por el mismo Espíritu que utiliza el santo para indicar la relación entre el Antiguo y el Nuevo Testamento (IIEp 9,9) sirve con mayor motivo para indicar la relación entre san Juan y san Pablo. Uno y otro tocan lo mismo, es decir, hablan de lo mismo. La nota es la misma: la caridad. Nada impide, pues, servirse del texto de uno para explicar un texto del otro. Su sintonía no se funda en criterios de simple simultaneidad cronológica o coincidencia espacial, criterios externos, sino en la unidad del mensaje salvífico revelado por Dios. De aquí la facilidad con que san Agustín pasa de san Juan a san Pablo. Asume que, siguiendo a san Pablo, lejos de apartase de san Juan (IIEP 9,1), lo entiende mejor.

El gramático y el teólogo suelen ir de la mano, aunque en unos momentos aparezca más visible el gramático y en otros el teólogo. A veces el teólogo se impone al gramático o el gramático cede la precedencia al teólogo. Como gramático, san Agustín encuentra en los textos paulinos términos que en sí mismos expresan conceptos idénticos o similares a los de Juan; como teólogo sabe que unos y otros proceden de la misma fuente de verdad. Para él, por tanto, las diferencias entre los dos autores sagrados nunca significan divergencias, sino aclaraciones, concreciones, complementos, aspectos parciales o ejemplos. Por ello, la adecuación de uno al otro, aunque de ordinario la apoye en una base filológica, recibe su fuerza de una base teológica. A partir de aquí los textos pueden modificar sus funciones: el de Juan servir de llamada y el de Pablo ofrecer la respuesta. Veamos ejemplos de cómo el teólogo se impone al gramático.

Hemos señalado antes como carencia en la exposición de San Agustín el no tomar en consideración los sujetos y objetos del amor de que hablan respectivamente los textos de san Juan y de san Pablo. Ahora bien, desde la teología este proceder tiene su coherencia en la implicación mutua de los distintos amores: el amor a los hijos de Dios conlleva el amor al Hijo de 
Dios y el amor al Hijo conlleva el amor al Padre, y lo mismo en el sentido inverso (IIEp 10,3). Por otra parte, siempre que ama el cristiano, ama Cristo en él, y en cierto modo ama el Espíritu, en cuanto dador del amor, y ama al Padre en cuanto que es su amor el que derrama el Espíritu en nuestros corazones. Por tanto, en su lógica teológica, el predicador se mantenía dentro del sentido del texto.

A propósito de IIEp 5,7, hemos objetado que san Agustín no ha advertido que se trata de distintos sujetos: en 1 Jn 3,9ab es Dios quien engendra; en 1 Cor 4,15c, Pablo mismo. Mas para el santo no hay problema en virtud de su teología del ministerio: el ministro es solamente eso, un ministro, porque, en definitiva, quien actúa desde dentro es siempre Dios. Teología que, por supuesto, tiene base bíblica, más específicamente paulina (1 Cor 3,6-7). Aunque en el pasaje no cita ese texto, no cabe dudar que está bien presente en la mente del predicador.

A propósito de IIEp 10,4, anotamos cómo san Agustín enfila una serie de textos que hablan del precepto o ley sea de Dios (preceptos de Dios [1 Jn 5,2]; ley de Dios [Sal 118,85]), sea de Cristo (ley de Cristo [Gál. 6,2]). Evidentemente, el gramático detecta que los complementos de los nombres son dos, lo que implica dos legisladores distintos; pero el teólogo advierte la unidad entre el Padre y Cristo, lo que le permite trascender el escrúpulo del gramático y utilizar el texto de Pablo para explicar el de Juan. La evidente distinción de personas divinas no era para él problema porque, desde la fe en el misterio trinitario, se acepta que ambas participan de una única naturaleza y que, además, actúan inseparablemente.

A propósito de IIEp 10,3, anotamos el solecismo que el gramático advertía en el hecho de usar primero el singular «hijo» (engendrado) y acto seguido el plural «hijos». Se trata de un problema advertido por el predicador gramático, pero superado por el predicador teólogo, en virtud de la doctrina teológica del Christus totus, presupuesta en la cita paulina (1 Cor 12,26-27). La conexión, pues, entre 1 Jn 5,2 y 1 Cor 12,26-27 no es de naturaleza gramatical, sino de naturaleza teológica.

A propósito de IIEp 10,5, se señaló cómo san Agustín había concluido, a partir de $1 \mathrm{Jn} 5,2$, que Cristo es el fin. Para probarlo, aduce dos textos del Antiguo Testamento (Sal 19,1 y Sal 118,96a), que identifican el fin con el precepto, y otros dos del nuevo, específicamente paulinos, uno de los cuales -1 Tim 1,5- identifica el fin con la caridad, y otro -Rom 13,10b-con Cristo. Una vez más, el escrúpulo del gramático lo supera el teólogo, identificando a Cristo con la Caridad. En efecto, tal identificación es obra del teó- 
logo que, por la fe asume que Cristo es Dios y que sabe, por san Juan mismo, que Dios es caridad (1 Jn 4,8.16). Dando un paso más, por el mismo principio, introduce la Trinidad.

En todos los casos citados se repite la misma realidad: de un texto de san Juan el predicador concluye algo que, a primera vista al menos, no se halla en él. En todos los casos, el predicador tenía que superar algún escrúpulo de naturaleza gramatical, cosa que lograba mediante algún dato de naturaleza teológica que, por otra parte, tenía base bíblica. Se da, pues, una especie de círculo vicioso. La lectura de la palabra de Dios le ha llevado a la comprensión de Dios y luego la comprensión de Dios orienta la interpretación de su palabra de Dios. Un texto bíblico fundamenta una verdad teológica y, luego, la verdad teológica fundamenta la interpretación de un texto bíblico. Procedimiento circular que tiene su base en la doble unidad de la Escritura: de autor y de contenido o mensaje.

\section{c) Pastor}

El gramático que exponía a los fieles de Hipona la primera Carta de san Juan, además de teólogo, era pastor de una comunidad ubicada en unas coordenadas de tiempo y espacio muy concretas y con una problemática específica. A ella tenía que servir en su función de expositor de la palabra de Dios. A ello se añadía, de una parte, que la palabra de Dios es de naturaleza salvífica y, de otra, que la búsqueda de una utilidad estaba contemplada también en la actividad del grammaticus. Aunque esa utilidad era, primariamente, de carácter formativo para el alumno independientemente del «arte» o profesión de que se tratase, entraba también en juego la formación ética ${ }^{32}$.

Para entender el influjo que ha tenido la realidad eclesial en el recurso a san Pablo por el comentador de san Juan, es necesario presentarla aunque sea muy brevemente. Los Tractatus fueron predicados en un momento de máxima tensión entre la Iglesia católica y la iglesia cismática donatista que había sufrido un duro golpe de parte del poder civil. Mediante un decreto del 12 de abril del 405, el emperador Honorio había aplicado a los donatistas las leyes antiheréticas con las duras sanciones que implicaban.

\footnotetext{
${ }^{32}$ De los grandes poetas se busca extraer una verdadera y legítima moral, siendo los estoicos los que más empeño pusieron en ello (cf. H. I. MARrou, Storia della educazione nell'antichità. Studium, Roma 1950, 230-231).
} 
Esta situación influyó en buena medida en la interpretación de la carta juánica por parte del pastor de Hipona, solo dos años después. La presencia del donatismo en ella es mucho mayor de lo que permiten suponer las raras menciones explícitas sea de epónimo Donato, sea de sus secuaces (cf. IIEp $1,13 ; 2,3 ; 2,4[2], 3,7)$.

La rival Iglesia donatista representaba un cisma dentro de la comunidad cristiana, con lo que significaba de rotura de la unidad y de ausencia del amor que la funda. Es cierto que la primera Carta de san Juan ofrecía a su expositor la insistencia en el amor fraterno como arma contra el cisma; cabe pensar incluso que, si el santo tomó como clave «exclusiva» de interpretación el tema de la caridad, se debió también ${ }^{33}$ a ese contexto eclesial. Pero cabe pensar asimismo que el santo no quería renunciar a la rica doctrina paulina del amor, que contenía un complemento que consideraba necesario. En efecto, si san Juan le brindaba la insistencia en el amor fraterno, no le ofrecía nada explícito sobre la unidad, término que no pertenece al vocabulario de la carta de san Juan ${ }^{34}$, pero bien presente en el texto agustiniano. La necesidad y el fundamento de la unidad de los cristianos la encontraba, en cambio, en san Pablo, particularmente en la doctrina del Christus totus, del Cristo. El pastor de Hipona, que entiende la carta apostólica como oportuna palabra de Dios para su comunidad, busca en san Pablo las claves de esa oportunidad. Lo vamos a ver en relación con la cristología, con la doctrina sacramentaria y con la doctrina sobre el amor.

San Agustín interpreta correctamente al apóstol Juan al ver en los anticristos a los herejes y cismáticos, con la particularidad de que ve en ellos a los disidentes de la Iglesia católica de su época, los donatistas. Este dato no podía quedar sin influjo en la interpretación agustiniana del texto juánico. El punto que marcaba la diferencia era el criterio en virtud del cual se era o no se era anticristo. Cuando fue escrita la carta de san Juan, estaba en discusión la persona de Jesús, diversamente entendida por los miembros de la comunidad a la que fue dirigido el escrito y por un grupo de disidentes que habían acabado separándose de ella. Mientras aquellos unían la persona histórica de Jesús con el Cristo y el Hijo de Dios, estos la separaban. En cambio, la situación que san Agustín tenía ante sí era otra, dado que la comunidad católica y la donatista tenían idéntica comprensión de la per-

\footnotetext{
${ }^{33}$ Aunque san Agustín no aduce esta razón (cf. IIEP prol).

${ }^{34}$ Aunque si habla de comunión (societas) con Dios (IIEp 1,5) y con los enemigos (Ibíd. 1,9). No obstante, valora poco estar en comunión con otros hombres (Ibíd. 1,3).
} 
sona de Jesucristo y proclamaban la misma $\mathrm{fe}^{35}$. Esta realidad explica la perspectiva menos doctrinal y más moral-espiritual con que se acerca san Agustín a estos temas y también el recurso a determinadas citas paulinas.

$\mathrm{Al}$ exponer, en IIEp 3,4,1 Jn 2,18-19 donde san Juan presenta como anticristos -los que se oponen a Cristo- a los disidentes de la comunidad, san Agustín invita a sus oyentes a examinar si personalmente son o no un anticristo. Como criterio de discernimiento le servía el criterio objetivo de san Juan, la separación de la comunidad; le servía también el motivo, la discrepancia cristológica, solo que actualizada: no el ser personal de Jesucristo, sino su ser «entero», es decir, el Christus totus, Cabeza y Cuerpo. Y para llegar a esta idea cita 1 Cor 12,26 que presenta a los fieles como miembros del cuerpo de Cristo. El anticristo no es ya quien discrepa respecto a la persona de Cristo, sino quien rompe la concordia entre los miembros del Cuerpo de Cristo. El gramático nunca llegaría a esta conclusión, pero sí el teólogo pastor de la comunidad.

En 1 Jn 2,22 san Juan identifica al anticristo con quien niega que Cristo ha venido en la carne. Al tratar de identificar al anticristo en IIEp 6,13, el predicador abandona luego el criterio doctrinal y pasa al moral, tomándolo precisamente de Tit 1,16 (Confiesan conocer a Dios, pero lo niegan con los hechos). Según él, niega con los hechos que Cristo viniera en carne el que carece del amor que motivó el que Cristo viniera así para morir por nosotros, que constituye la mayor prueba de amor (Jn 15,13). Tales son, en la mente del predicador, los donatistas que carecen de ese amor, como lo prueba su separación. Aunque el gramático podía establecer la conexión entre el texto juánico y el paulino, apoyándose en la idea común de «negar», como los contextos son diversos y diverso el complemento del verbo, la interpretación dada hay que ponerla sin duda en el haber del pastor.

En IIEp 6,14 y siempre en relación con 1 Jn 2,22, nuestro exegeta insiste todavía en que ha de aplicarse el criterio de los hechos. Esta vez la prueba, sorprendente, la encuentra en 1 Jn 4,3 ( $Y$ ningún espíritu que quiebre-disgregue-a Cristo, negando que vino en la carne, es de Dios $\left.{ }^{36}\right)$. Pero solo en-

${ }^{35}$ A pesar de los posibles flirteos entre arrianos y donatistas. Cf. Pedro LANGA, "El concilio semiarriano de Sérdica", nota complementaria 42, en Obras Completas de san Agustín, vol. XXXIi, BAC 498, Madrid 1988, 904-906.

${ }^{36}$ «Él vino a reunir, tú a disgregar. Pretendes disgregar los miembros de Cristo. ¿Cómo sostienes que no niegas que Cristo ha venido en la carne tú que disgregas la Iglesia de Dios que él congregó? Vas, pues, fuera de Cristo; eres un anticristo...» (IIEp 6,14). 
tenderá su lógica quien advierta que en este caso se sirve de solvere («romper», «disgregar») y no de negare («negar») -el verbo que utiliza en el resto del comentario- o confiteri («confesar»). En la interpretación del obispo, quienes niegan que Cristo ha venido en la carne son los donatistas porque disgregan a Cristo al disgregar-dividir-a la Iglesia. Dado que el argumento se funda en el término «disgregar» (solvere) hay que reconocer al gramático su papel; pero también que su actuar, anómalo -cambiar solo aquí el verbo «negar» por «disgregar»-, tenía detrás al pastor, que buscaba dejar en mala luz ante sus oyentes a los donatistas, mostrando que no son de Dios.

Según 1 Jn 5,1, al creer que Jesús es el Cristo, el cristiano muestra haber nacido de Dios, por lo que, si ama a Dios Padre de quien Cristo ha nacido, amará asimismo a los demás cristianos, hijos también de Dios. Detrás de esta interpretación que, en IIEp 10,2, distingue entre el Hijo natural de Dios y sus hijos adoptivos tiene -como señalamos en un apartado anterior-al teólogo, pero probablemente también al pastor, que quería mostrar a sus fieles -contra los donatistas- que no se puede amar al Hijo de Dios, sin amar a sus otros hijos, miembros de su cuerpo. Además, el recurso a la cita de Gál 5,6 sirve al mismo objetivo; le permitía mostrar que el amor no es un simple corolario de la fe (así san Juan), sino que la especifica; que la fe auténtica no es sin más la que acepta determinado contenido doctrinal, sino con la que actúa por el amor. Y como los donatistas no poseen el amor, dado que se han separado, tampoco tienen fe. Aunque el recurso al texto paulino caía dentro de la lógica del gramático -tanto 1 Jn 5,1 como Gal 5,6 hablan del amor-, su utilización hay que atribuirla antes al pastor.

Los católicos divergían de los donatistas también en la doctrina sacramentaria, en concreto en el papel de los ministros que administraban los sacramentos. Según los católicos, los ministros eran eso y nada más, es decir, ministros de Cristo, quien propiamente confiere la gracia; según los donatistas, son los ministros mismos lo que la confieren. En consecuencia, los católicos admitían la validez de los sacramentos de los cismáticos, pero los cismáticos rehusaban admitir la validez de los sacramentos católicos. A partir de este planteamiento ¿qué distingue los sacramentos administrados por un católico de los administrados por un donatista? El predicador de Hipona pone el criterio diferenciador en el ámbito moral: la caridad en el corazón discernida en la presencia de Dios.

Bautismo. El contexto bautismal en que fue escrita la carta de san Juan y el contexto pascual en que fue expuesta por san Agustín dan razón de la 
reiteración con que san Agustín vuelve sobre el sacramento del bautismo al exponer el texto apostólico.

Al comentar, en IIEp 2,4, 1 Jn 2,12 (vuestros pecados os son perdonados en su nombre), el predicador apostilla: «no en el (nombre) de Pablo, o en el de Pedro, o en el de Donato», no dejando duda de la intencionalidad antidonatista de su exposición. Esa apostilla es eco de 1 Cor $1,13 \mathrm{bc}$ (¿Acaso fue crucificado Pablo por vosotros? ¿O habéis sido bautizados en el nombre de Pablo) que ha citado. El recurso a esta cita cabe en la lógica del gramático porque tanto $1 \mathrm{Jn}$ 2,12 como 1 Cor 1,13bc coinciden en referirse a algo realizado en nombre de alguien, pero también y con más razón, al teólogo y al pastor: al teólogo porque le sirve para exponer la teología bautismal católica y al pastor porque le sirve para condenar las banderías entre los seguidores de Cristo.

El comentario, en IIEp 2,9, a 1 Jn 2,15 (Si alguien ama el mundo, el amor del Padre no está en él) lo deriva el predicador hacia la teología sacramentaria bautismal. El punto de conexión es la idea del amor del Padre que cuadraba bien en contexto pascual en que los neófitos habían sido hechos hijos de Dios por el bautismo. Luego, con una alusión a 2 Tim 3,5, distingue entre la forma y la virtus -la validez y la eficacia del sacramento-, señalando que la virtus le viene de la caridad. Dos textos paulinos sostienen su tesis: con 1 Cor 11,29-simple alusión-muestra que un sacramento -aquí la afirmación es general ${ }^{37}$ - mal recibido se puede convertir en causa de condenación; con Ef. 3,17b muestra que, a fin de que sea para él garantía de salvación, el que lo recibe ha de estar arraigado en la caridad. No es fácil encontrar una razón de base gramatical que llevase al gramático a vincular 1 Jn 2,15 con 2 Tim 3,5; en cambio, se entiende perfectamente la vinculación por obra del teólogo y pastor. El texto paulino servía al teólogo para exponer la doctrina sacramentaria católica y al pastor para mostrar que el amor del Padre no estaba en los donatistas.

En IIEp 5,6 procede de idéntica manera al orientar su comentario a $1 \mathrm{Jn}$ 3,9 (quien ha nacido de Dios no peca) hacia la teología sacramentaria. Al teólogo no le resultaba difícil porque en el bautismo se produce de hecho ese «nacer de Dios». Y al pastor le interesaba mostrar que los donatistas no po-

${ }^{37}$ En IIEp 2,1 utilizará el mismo texto pero referido a la eucaristía como en san Pablo. Pero aquí no es reclamado por ningún pasaje de la carta apostólica, sino por Lc 24,28-30, pues en la liturgia eucarística se había leído el relato lucano sobre el encuentro de Jesús con los discípulos que se encaminaban a Emaús (Lc 24,13-32). 
dían acogerse a ese «no peca» en virtud del «haber nacido de Dios». Tenía que probar que de la recepción del bautismo no se sigue automáticamente ese nacer de Dios, pues la consecuencia está vinculada a la posesión de la caridad: «vea si tiene la caridad y, si es así, diga: "he nacido de Dios"». Es, pues, al pastor, más que al gramático, al que cabe atribuir el recurso a 1 Cor $13,2 \mathrm{bc}$.

Según 1 Jn 3,14 conocemos que Dios permanece en nosotros por el Espíritu que se nos ha dado. La mención del Espíritu lleva al teólogo, en IIEp 6,10; a pensar en Pentecostés y en el bautismo, en el que se recibe el Espíritu. Pero al pastor le importaba sobre todo que sus fieles, que habían recibido el bautismo, supieran si habían recibido también el Espíritu. Su presupuesto era que los donatistas que habían recibido el primero no habían recibido el segundo. El criterio no será otro que el amor: «Si en él hallas el amor fraterno, quédate tranquilo. No puede haber amor sin el Espíritu de Dios». En el haber del pastor hay que poner, pues, la cita de Rom 5,5b que le sirve de apoyo en este contexto específico, aunque también en cuanto gramático cabía el que hiciese uso de ella, partiendo de que la mención del Espíritu aparece en ambos textos.

Orden. En IIEp 1,7-8 san Agustín comenta 1 Jn 2,1 ( $Y$ si alguno peca, tenemos un abogado ante el Padre, a Jesucristo el justo, que es propiciador por nuestros pecados). Polemizando con los donatistas, señala que el apóstol Juan habló en primera persona («tenemos»), no en segunda («tenéis»), es decir incluyéndose a sí mismo entre los pecadores, y que puso como abogado a Cristo, no a sí mismo. El gramático podía detectar una conexión entre la condición de abogado y el hecho de orar por alguien, pero el razonamiento es más bien obra del teólogo y sobre todo del pastor; a uno y otro hay que asignar el recurso a Col 4,3a (Orando al mismo tiempo también por mî), que contempla la intercesión de los fieles por sus pastores y, como a fortiori, de los pastores por sus fieles, y la alusión a Ef 1,23 que presenta a Cristo como cabeza de la Iglesia, que es donde se halla la base de su argumento: en definitiva, quien intercede es Cristo, Cabeza de la que los fieles son miembros. De esta manera, refuta ante sus fieles la tesis donatista: «Nada tiene de extraño, pues, que siga y tape la boca a los que dividen la Iglesia de Dios».

La afirmación de 1 Jn 2,27 de que la misma Unción instruye a los cristianos sobre todas las cosas, pone a san Agustín ante un gran misterio (magnum sacramentum): ¿para qué habla entonces el predicador? El texto de 1 Cor 3,6- 
7 a que recurre el predicador sugería poco al gramático, pero era fundamental para el teólogo, al que le permitía distinguir y, a la vez, conciliar la actuación de Dios y del ministro de la Iglesia y así afirmar la teología sacramental católica frente a la donatista, y para el pastor en su preocupación por afianzar a los católicos frente a los donatistas.

Amor. En IIEp 1,12 el predicador da el salto de un concepto básico en san Juan, el amor al hermano, a otro concepto esencial en la controversia con los donatistas, la unidad, utilizando a san Pablo como fuente privilegiada, aunque no exclusiva. Punto de partida es $1 \mathrm{Jn}$ 2,10 (Quien ama a su hermano permanece en la luz y no tropieza). Desde la posición del gramático se puede justificar el recurso a 2 Cor 11,29 (¿Quién tropieza sin que yo me abrase?) y a Sal 118,165 (Haya paz abundante para los que aman tu ley y no tendrán dónde tropezar), en razón de la presencia en los tres textos del verbo «tropezar». Pero es el pastor el que justifica el servirse de ellos y también de otra serie de textos como Sal 120,6 (De día no te quemará el sol ni la luna de noche), Jn 13,34 (Os doy un mandamiento nuevo...) y Gál 6,2 (Llevad mutuamente vuestras cargas; así cumpliréis la ley de Cristo), mediante los cuales ha dado concreción al amor fraterno inicial (1 Jn 2,10) hasta convertirlo en amor a la unidad (de la Iglesia) que implica tolerar y llevar las cargas de los demás. De esta manera indicaba a sus fieles el modo de actuar también con los donatistas.

En IIEp 6,2, san Agustín se ocupa de 1 Jn 3,18, texto en que el apóstol Juan invita a discernir el amor mediante las obras. Pero a san Agustín eso no parecía bastarle porque las «obras» que realizaban católicos y donatistas eran básicamente idénticas. Para él era imprescindible discernir entre unas y otras. Mirando a ese objetivo trae a colación la obra buena referida en 2 Cor 12,15a, discernida en 1 Cor 4,3; luego cita 1 Cor 13,3 que presenta varias obras en sí mismas buenas, pero que también han de ser discernidas en el propio corazón en presencia de Dios, y finalmente 2 Cor 12,1a, Gál 6,4 y Gál 4,4, textos que avalan lo anterior con la praxis de san Pablo. Es evidente que aquí ha sido sobre todo el pastor el que ha guiado la selección de citas paulinas. Con ellas ha quitado valor a las obras de las que presumían los donatistas. Otro caso similar -siempre como extensión del comentario de 1 Jn 3,18-aparece en IIEp 8,9, donde el pastor recurre a 1 Cor 13,3 para mostrar que hay actos heroicos que pueden provenir del orgullo y no del amor, lo que hace que carezcan de todo valor religioso, y concluir que hay que entrar en el propio corazón para interrogarlo. 
En IIEp 7,11 el predicador prolonga el comentario de 1 Jn 4,10 (Él nos amó y envió a su Hijo como propiciación por nuestros pecados) con la cita «paulina» de Heb 12,6-7 (...azota a los hijos que acoge...), aducida como prueba de que la caridad no es desidiosa, sino activa y, a la vez, al menos aparentemente, dura. La cita podía ser solicitada por el gramático, dado que ambos textos coinciden en la idea de sufrimiento ${ }^{38}$ (propiciación/azote), pero quizá se ajuste mejor a la realidad asignarla al pastor, que posiblemente pretendía buscar una justificación de las medidas tomadas por el poder imperial contra los disidentes donatistas y aceptadas por la Católica. Lo mismo cabe decir a propósito de IIEp 8,11. Detrás de la cita de Heb 12,6b, aducida tras cuestionarse por qué san Juan no recomienda el amor a los enemigos, hay que ver también y por las mismas razones al pastor.

Hemos pasado revista a diversos textos con los que hemos tratado de mostrar cómo la función del teólogo/pastor se sobrepone a la del gramático en el recurso a san Pablo para interpretar a san Juan. Un pastor al que atormenta la presencia de los disidentes donatistas en medio de su grey. Son ejemplos claros de explicación de san Juan en clave antidonatista al amparo de textos paulinos. El pastor Agustín ha actualizado el texto de la Carta juánica. El peso que esta realidad ha tenido en la interpretación agustiniana se advierte de modo especial en el hecho de que la separación entre Jesús y Cristo de la carta de san Juan se transforma en el comentario agustiniano en separación entre Cabeza y Cuerpo, es decir, entre Cristo y la Iglesia (IIEp 6,14), en la teología sacramentaria de los Tractatus referida a los sacramentos del bautismo y orden, en la insistencia en autentificar no tanto las obras, cuanto la raíz de donde brotan. Siempre cabe preguntarse cuál hubiera sido la ruta seguida por el predicador de Hipona de haberse hallado en otro contexto eclesial. Puro futurible, la pregunta siempre quedará sin respuesta, pero no cae fuera de lógica asumir que en el caso de haber tenido ante sí otro contexto eclesial, hubiese recurrido a otros textos, no siempre paulinos, pero sobre todo paulinos. A la idea a san Juan se sobrepone el interés pastoral de san Agustín. La conexión de naturaleza filológica entre los textos se sustituye o se complementa con otra que el teólogo deriva del texto y sirve a las intenciones del pastor. El teólogo no cabe verlo separado del pastor. Su teología ha surgido en la brega a que le obligaba el servicio pastoral.

\footnotetext{
${ }^{38}$ Siempre que se presuponga que esa propiciación tuvo lugar mediante la cruz.
} 
Por mucho que preocupara al pastor la realidad de la disidencia cismática, no era su única preocupación. También le preocupaba por supuesto la vida cristiana de sus fieles. Y también ella ha repercutido en el recurso de san Agustín a los textos paulinos.

Como primer ejemplo sirva la exposición de $1 \mathrm{Jn}$ 3,6: Todo el que peca ni le ha visto ni le ha conocido (a Dios). En IIEp 4,8 el texto le evoca a san Agustín 2 Cor 5,6c-7 que distingue entre el conocimiento por fe y el conocimiento por visión. Obviamente la asociación podía haberla hecho el gramático sobre la idea del conocimiento presente en ambos textos, pero probablemente viene del pastor, interesado en tranquilizar a sus fieles a los que, al saberse pecadores, les entraba la duda de si efectivamente habían conocido a Dios.

San Juan sostiene en 1 Jn 3,9 que el que ha nacido de Dios no puede pecar. En IIEp 5,3, san Agustín interpreta la afirmación referida a un pecado específico: el pecado contra el amor fraterno. Según él, es imposible que el amor fraterno, si ha alcanzado su perfección, peque contra el hermano. Entonces cita 2 Cor 2,12.15 y Fil 1,21.23-24, junto con Jn 21,17 y Sal 115,12-13 para mostrar dicha perfección en Pablo. Tales citas paulinas no se deben al gramático, sino al pastor que deseaba no solo defender la no contradicción interna del texto juánico y la contradicción con la experiencia del cristiano que continuamente sufre los zarpazos del pecado.

En IIEp 6,5-8, san Agustín se ocupa de 1 Jn 3,22 (Tenemos confianza en Dios y todo lo que le pidamos lo recibiremos de él porque cumplimos sus mandamientos). El pasaje le solicita, primero, 2 Cor 12,7-9a-c; luego Rom $8,26 \mathrm{bc}-27 \mathrm{c}$ y finalmente Rom 5,5b. La coincidencia de los dos textos paulinos con el san Juan en el tema de la oración abría las puertas al gramático; con todo, el recurso a ellos hay que asignarlo al pastor, que necesitaba mostrar la verdad de la afirmación de san Juan de que la oración será escuchada, al parecer contradicha por la experiencia de muchos fieles, cansados de pedir al Señor y no recibir nada. Si el primer texto parece confirmar que san Pablo vivió en sus propias carnes la misma experiencia de los fieles, el segundo, a la vez que asegura, también por la experiencia del Apóstol, la veracidad de lo afirmado por san Juan, da la explicación de la percepción contraria: el cristiano recibe lo que desea -siempre que sirva a su salvación-, aunque no siempre lo que pide. Como él no sabe pedir lo que le conviene, lo hace el Espíritu por él. El tercer texto lo reclama el teólogo pues, al vincular Espíritu y amor, puede concluir que es el amor el que ora. 


\section{Ideas paulinas preponderantes}

Nos parece evidente que san Agustín interpreta repetidamente a san Juan desde san Pablo. Ahora cabe preguntarse qué puntos del pensamiento paulino adquieren especial relevancia en estos Tractatus sobre la primera carta de san Juan. Destacamos los siguientes: la doctrina del Cuerpo de Cristo, las dos etapas del cristiano, la condición enfermiza del hombre, el mayor énfasis en la pasión y muerte de Cristo que en la encarnación, la teología del amor.

\section{a. La doctrina de Christus totus.}

Aunque la expresión «Cristo entero» (Christus totus) no es paulina, sino agustiniana, su contenido doctrinal sí lo es. Paulina es efectivamente la fuente en que se inspira el santo (cf. Rom 12;4-8 1 Cor 12,4ss; Ef 1,22-23; 5,23.27; Col 1,18, etc). Si en su tenor literal aparece solo una vez en el conjunto de los Tractatus, como concepto está muy presente en ellos. Un repaso a los textos comentados permite advertir el recuso a esa doctrina en relación con la intercesión de los ministros por sus fieles, con el autor del bautismo, con la identificación de los anticristos, con el paso de la caridad al amor fraterno, con solecismos. Veámoslos.

La aparente discordancia entre $1 \mathrm{Jn} 2,1$ (... Jesucristo el justo, que es propiciador por nuestros pecados) y $\mathrm{Col} 4,3 \mathrm{a}$ (Orando al mismo tiempo también por mi) lleva al predicador a plantear, en IIEp 1,7-8, la cuestión de la intercesión de los ministros de la Iglesia. La solución que aporta pasa por Col 1,18, es decir por la concepción teológica que considera a Cristo como cabeza de la Iglesia, su cuerpo. Así fundamenta la praxis eclesial de la intercesión de los pastores por sus fieles, sin negar que Cristo sea el propiciador por nuestros pecados. La teología del Christus totus sitúa la respuesta agustiniana en la teología católica y la aleja de la donatista.

La indicación de san Juan de que nuestros pecados nos son perdonados por el nombre de Jesucristo (1 Jn 2,12) lleva al predicador, en IIEp 2,4, a 1 Cor $1,13 \mathrm{c}$, en que Pablo pregunta a los corintios si han sido bautizados en su nombre. Ahora bien, las palabras que san Agustín pone en boca de san Pablo como respuesta a su propia pregunta retórica se entienden dentro de la doctrina del Christus totus: «¿Qué dice? No quiero que estéis de mi parte para que podáis estar conmigo... Todos somos de aquel que murió por nosotros, y por nosotros fue crucificado». «Estar conmigo» en Cristo «de quien todos somos» miembros, hay que sobrentender. 
En su deseo de «actualizar» la figura del disidente de 1 Jn 2,18-19 (han aparecido muchos anticristos... que salieron de la comunidad cristiana, pero que no pertenecían a ella), en IIEp 3,4, se sirve de 1 Cor 12,26, lo que equivale a decir de la doctrina del Christus totus: «El que no está contra Cristo se mantiene adherido a su Cuerpo y se le tiene por uno de sus miembros. Nunca un miembro está contra otro. La integridad de un cuerpo es resultado de contar con todos sus miembros... Por tanto, entre los miembros concordes no hay anticristo alguno». En el trasfondo siguen estando los donatistas.

De igual manera, para probar en el mismo contexto que es anticristo todo el que niega que Cristo ha venido en la carne (1 Jn 2,22), en IIEp 6,14 aduce 1 Jn 4,3 en versión propia: $Y$ ningún espíritu que quiebre-disgreguea Cristo, negando que vino en la carne, es de Dios. Ahora bien, ese disgregar a Cristo lo entiende en el sentido de disgregar los miembros de Cristo, detrás de lo cual se halla la doctrina del Christus totus. Lo que en san Juan consistía en separar a Jesús del Cristo, en el texto agustiniano consiste en separar a Cristo cabeza de su Cuerpo, la Iglesia. El predicador ha llegado a adaptar el texto de san Juan para poder explotar, a partir de él, la idea del Christus totus.

Para superar lo que puede parecer una contradicción entre 1 Jn 3,9 (el que ha nacido de Dios no peca) y $1 \mathrm{Jn} 1,8$ (El que diga que no tiene pecado es un mentiroso), san Agustín sostiene, en IIEp 5,3, que en el primer caso san Juan se refiere al pecado contra el amor fraterno. Como ejemplo de ese amor presenta a Pedro quien para agradecer al Señor, con palabras del salmista, todo lo que le ha dado, está dispuesto a tomar el cáliz de la salvación. Esto significa que el amor de Pedro a Cristo (Jn 21,17) alcanza su plenitud en el tomar el cáliz de la salvación, esto es, en entregar la vida por los demás. El paso del amor al Señor al amor fraterno tiene lugar en relación con Cristo. Estamos de nuevo, sin referencia explícita, dentro de la teología del Christus totus.

El paso del singular en 1 Jn 5,1 -el «engendrado»-al plural en 1 Jn 5,2 -los «hijos»- parece representar una incorrección gramatical. Para mostrar que tiene lógica, el santo recurre, en IIEp 10,3, a la teología del Christus totus, que subyace a 1 Cor 12,26-27. Esa doctrina le permite ver en el «engendrado» a Jesucristo, en cuanto Cabeza y en los «hijos» a los cristianos en cuanto miembros de su Cuerpo: «los hijos de Dios son el cuerpo del Hijo único de Dios. Y, dado que él es la Cabeza y nosotros los miembros, no hay más que un único Hijo de Dios. Por tanto, quien ama a los hijos de Dios ama al Hijo de Dios». 
El repetido recurso al concepto del Christus totus, aún cuando faltan textos que pueden facilitar la conexión con la idea, manifiesta la familiaridad del predicador y de sus fieles con ese planteamiento teológico. Sirve para resolver problemas que le suscita el texto juánico y, al mismo tiempo, para argumentar contra los donatistas.

\section{b. Las dos etapas de la existencia cristiana}

En 1 Jn 3,2 san Juan hace referencia a dos etapas de la condición cristiana, una en el presente, otra en el futuro escatológico: Ahora somos... aún no se ha manifestado lo que hemos de ser. La segunda etapa se define en términos de visión de Dios, en virtud de lo cual seremos semejantes a él. Nada extraño, pues, que ambas etapas aparezcan en los Tractatus. Pero hay otros datos al respecto que llaman la atención. Veamos los textos.

Al comentar 1 Jn 3,2, el predicador centra primero su atención en el verbo es que, en cuanto indicador de la inmutabilidad divina, le remite a Jn 1,1 y a Fil 2,6; luego señala que, cuando Jesucristo venga a juzgar, los impíos solo lo verán en su forma humana, no en la divina, mientras que los justos han de contemplarlo en cierta visión que ni ha visto el ojo, no ha oído el oído, ni ha llegado al corazón del hombre (cf. 1 Cor 2,9bd). 1 Cor 2,9bc-aquí simple referencia- sirve al predicador para contraponer el conocimiento de Dios que procura la fe-sugerida por la cita de Mt 5,8 (los limpios de corazón verán a Dios) - al que proporcionará la futura visión de Dios (1 Cor 2,9bc). El santo confirma lo referido por san Juan - la visión plena de Dios (como es) es realidad futura, escatológica- negando que se dé ya en esta vida.

Ante la mención por san Juan de la justicia en 1 Jn 2,29 (todo el que obra la justicia ha nacido de Dios), el predicador se apresura, en IIEp 4,3, a indicar, siguiendo a san Pablo, que proviene de la fe (Rom 1,17d; Gál 3,11c) y a señalar sus dos etapas: una incipiente, que consiste en el reconocimiento de los propios pecados (cf. Sal 146,7), y otra plena, cuando la muerte sea absorbida en la victoria (cf. 1 Cor 15,54), cuando ninguna apetencia humana atraiga, cuando desaparezca toda lucha con la carne y la sangre, cuando se alcance la corona de la victoria, el triunfo sobre el enemigo (cf. 1 Cor 15,55-57). De estas dos etapas de la justicia habla también en IIEp 4,8, aunque de forma menos clara.

El problema que plantea la afirmación de san Juan de que todo el que peca no ha visto ni conocido a Dios (1 Jn 3,6bc) -implicaría que nadie lo ha 
conocido, porque nadie puede decir que no tiene pecado (cf. 1 Jn 1,8)- lo resuelve el santo, en IIEp 4,8, recurriendo a las dos etapas señaladas por san Pablo en 2 Cor 5,6c-7, que permiten hablar, alejándose de lo afirmado de san Juan en ese texto, de una iluminación en el presente que proviene de la fe y de otra futura que vendrá de la visión.

San Juan afirma que el Padre envió a su Hijo como salvador/sanador del mundo (1 Jn 4,14). Si no cabe dudar de ello, ¿cómo ha de entenderse esa sanación, si resulta incuestionable que el hombre sigue siendo un enfermo? Para resolver el problema, en IIEp 8,13, el predicador acude de nuevo a san Pablo y distingue dos etapas: una inicial, vinculada a la adquisición de la fe (Rom 8,24a), y otra de plenitud, «cuando esto corruptible se revista de incorruptibilidad y esto mortal se revista de inmortalidad (cf. 1 Cor 15,5354)», objeto ahora de esperanza, aún no de posesión.

La mención por san Juan de la caridad plena, caracterizada por tener confianza en el día del juicio (1 Jn 4,17), lleva al predicador, en IIEp 9,2, a admitir etapas en la posesión de la virtud: una incipiente que se caracteriza por el temor ante el día del juicio, y la otra de plenitud, definida por la confianza, como acabamos de decir. En otros términos, el santo distingue la etapa del temor de que venga Cristo de la etapa del deseo de su venida (Mt 6,10; Sal 6,4-5), hallando en san Pablo el ejemplo más claro (Fil 1,23c-24). A diferencia de los demás ejemplos, en el presente las dos etapas tienen lugar en el curso de la vida presente.

A través de Sal 118,96a, san Agustín vincula los mandamientos de 1 Jn 5,2 con la idea del fin en el que todo alcanza su plenitud. Después de un largo desarrollo de citas bíblicas, sobre todo paulinas, en IIEp 10,5 concluye que Cristo -que en cuanto Dios es también caridad- es el fin, la meta, y que todo lo demás no es más que camino hacia él. Por ello invita a los fieles a seguir la ruta hasta el fin, sea la que sea la etapa del recorrido en que se encuentre, hasta adherirse a Dios (cf. Sal 72,28), pero en la patria. La idea de que los cristianos pueden hallarse en diferentes etapas de su caminar hacia Dios vuelve a aparecer en el apartado siguiente, IIEp 10,6, en el que el predicador continúa con el mismo discurso. La diferencia está en que ahora el fin o la meta la toma del mismo san Juan: Somos hijos de Dios y aún no se ha manifestado lo que seremos (1 Jn 3,2). Y el santo comenta: El cristiano, por tanto, está en camino; sea la que sea la etapa alcanzada, ha de dejarla atrás hasta llegar a determinado fin: Sabemos que, cuando se manifieste, seremos semejantes a Él porque le veremos como es (1 Jn 3,2) (IIEp $10,6)$. 
De lo expuesto se pueden sacar estas breves conclusiones: los Tractatus manifiestan la centralidad que su autor otorga a las etapas en la existencia cristiana. Estas etapas las entiende, en unos casos, pertenecientes al curso de la existencia terrena; en otros, pertenecientes, respectivamente, al tiempo presente y al futuro escatológico. En el primer caso, subyace una comprensión de la vida cristiana en continuo desarrollo en la experiencia del amor: de un amor que va acompañado del temor, a un amor caracterizado por la confianza; como un hacer el camino hasta llegar a la meta. En el segundo caso, subyace una comprensión de la vida cristiana que va del reconocimiento de los propios pecados, o de la penumbra de la fe, o de la esperanza de curación, en la vida presente, a la victoria plena sobre el pecado y al triunfo sobre el enemigo, a la claridad de la visión, a una salud caracterizada por la incorrupción y la inmortalidad, en la vida futura. Los textos que le iluminan para establecer ambas etapas no son tanto 1 Jn 3,2 como los paulinos 1 Cor 2,9bd; 1 Cor 13,12 o 2 Cor 5,6c-7, y para la descripción de la segunda etapa 1 Co 15,53-57. A su vez, llama la atención que la idea se la susciten textos juánicos como 1 Jn 2,29;3,6bc; 4,14; 4,17; 5 ,2 que en sí mismos nada dicen al respecto. La conclusión que se puede extraer resulta clara: el predicador de Hipona toma pie de textos juánicos para introducir ideas paulinas. El predicador ha introducido las categorías del «ya, pero todavía no» para solucionar cuestiones que, a su modo de ver, planteaba la lectura del texto de san Juan. Pero ni el «ya», ni el «todavía no» son interpretados en la perspectiva del texto de san Juan que presupone esas etapas.

\section{c. La condición enfermiza del hombre}

San Juan afirma que todo hombre es pecador y que, por consiguiente, si alguien osa sostener lo contrario, en él no mora la verdad (1 Jn 1,8). Afirma incluso que el Padre envió a su Hijo al mundo para salvar al mundo (1 Jn 4,14). Pero, según él, el hombre se hace pecador, no nace pecador; su pecado es siempre personal. El predicador hace suya la idea del hombre pecador, pero entiende diversamente esa condición pecadora. Como ejemplo de ello, valgan los siguientes textos.

La carta apostólica habla de las obras del diablo para cuya destrucción se manifestó el Hijo de Dios (1 Jn 3,8cd). Pero mientras san Juan piensa en pecados concretos del hombre, san Agustín contempla, en IIEp 4,11, el pecado que Adán trasmitió a todos sus descendientes. Es cierto que no emplea el término «pecado original», pero la realidad en que piensa es esa. Este 
texto no deja duda: «Por mediación de quien sólo era hombre, somos pecadores; por mediación del hombre Dios, nos hacemos justos. El nacimiento primero nos arrojó a la muerte, el segundo nos levantó a la vida. El primero arrastra consigo el pecado, el segundo libra del pecado» (cf. Rom 5).

Según san Juan, los cristianos son testigos de que el Padre envió su Hijo como salvador del mundo (1 Jn 4,14). Eso significa para el predicador, en IIEp 8,13, que el mundo estaba enfermo, pues «salvador» hay que entenderlo como «sanador», igual que «salvación» como «sanación». El mundo, pues, estaba enfermo y el mal del que necesitaba ser curado no era un mal cualquiera sino de tal magnitud que curarlo sólo estaba al alcance de un médico omnipotente. Esta idea es difícil inferirla del texto juánico, pero cuadra perfectamente dentro de las categorías de la antropología teológica del obispo de Hipona. La diferencia está en que mientras san Juan da a «mundo» un sentido restringido -el conjunto de quienes rechazan y se oponen a Dios-, san Agustín lo extiende hasta abarcar al conjunto de la humanidad, incluidos los apóstoles. El mal de que sufre toda la humanidad y del que vino a sanarla el médico celeste no es otro que el contraído en Adán. Los apóstoles fueron los primeros en ser curados y los que le dieron celebridad como médico.

San Pablo era uno más entre los enfermos y también él necesitaba curación. Comentando la afirmación de san Juan de que el cristiano tiene confianza en Dios y de que todo lo que pida lo recibirá de él, porque cumple sus mandamientos (1 Jn 3,21-22), el predicador, en IIEp 6,4-7, primero pone como objeción el caso de san Pablo que pidió y no recibió (cf. 2 Cor 12,79), pero inmediatamente afirma lo contrario, es decir, que Dios le escuchó, aunque matizando: no le otorgó lo que pedía, sino lo que le convenía para su sanación. Este particular se ajusta a la concepción agustiniana según la cual todo hombre se halla enfermo, en cuanto herido por el pecado de Adán, pero no encaja en la perspectiva de san Juan. La grave enfermedad de san Pablo de la que le curó el Señor vuelve a mencionarla en IIEp 8,2: «A Pablo le agrada que nosotros refiramos sus pecados para gloria de quien curó tan grave enfermedad». Pero entre los dos textos hay una significativa diferencia: en el primer caso el enfermo es Pablo ya convertido, mientras en el segundo es Pablo antes de su conversión, es decir, Saulo.

Como se ha podido ver, san Agustín ha tomado pie de la mención de san Juan de «las obras del diablo» y del pecado «del mundo» para introducir un concepto extraño a san Juan, el del pecado original, que él descubría en san Pablo. No lo menciona por su nombre, pero se sobreentiende en su 
argumentación. Incluso allí donde está claro que habla de pecados personales, como en el caso de san Pablo, la idea subyace a sus palabras; el pecado original es la raíz de la que proceden esos frutos amargos.

\section{d. La pasión y muerte de Cristo frente a la encarnación}

En la carta de san Juan está más presente el misterio de la encarnación del Hijo de Dios que el de su pasión y muerte. Este énfasis en la encarnación (cf. 1 Jn 2,22; 4,2-3.9) se explica porque los disidentes, al negar la identidad entre Jesús y el Hijo de Dios y el Cristo, la negaban. La pasión y muerte de Cristo solo aparece sobrentendida al presentarlo a él como propiciación por nuestros pecados (1 Jn 4,10). En el comentario del obispo de Hipona, en cambio, el centro de interés pasa de la encarnación a la pasión y muerte de Jesucristo, más en línea con la teología paulina.

San Juan prueba el amor del Padre hacia el cristiano con el hecho de haber enviado su Hijo al mundo para que vivamos por medio de él (cf. $1 \mathrm{Jn}$ $4,9)$, es decir, con su encarnación, y con el hecho de haberlo enviado como expiación de nuestros pecados (1 Jn 4,10). Curiosamente en su comentario, en IIEp 7,7, san Agustín, de una parte, pasa por alto la primera manifestación del amor divino - la encarnación- y se centra en la segunda -la muerte-; de otra, respecto de la segunda manifestación, aunque pasando por el evangelio de san Juan (Jn 15,13), parece que le falta tiempo para buscar la confirmación en san Pablo, recurriendo a Rom 8,32 (El que no perdonó a su propio Hijo, sino que lo entregó por nosotros, ¿cómo no nos ha dado ya todo con él?) y a Gál 2,20a (Quien me amó y se entregó a sí mismo por mí), obviando 1 Jn 4,10.

San Juan considera «jóvenes» a los cristianos a los que escribe porque han vencido al maligno ( $1 \mathrm{Jn} 2,13 \mathrm{~cd}$ ) y porque son fuertes (1 Jn 2,14f). El comentario agustiniano, en IIEp 2,6, se apresura a justificar esa fortaleza desde la pasión de Cristo: «Nos hizo fuertes el que no opuso resistencia a sus perseguidores, pues fue crucificado en razón de su flaqueza, pero vive por el poder de Dios (2 Cor 13,4ab).

En 1 Jn 4,19 san Juan invita al cristiano a amar porque Dios lo amó antes. Comentándolo en IIEp 9,9, san Agustín añade: «Escucha al apóstol Pablo: Dios nos mostró su amor en el hecho de que, cuando aún éramos pecadores, Cristo murió por nosotros (Rom 5,8). Él, justo, por nosotros impíos; Él, hermoso, por nosotros feos». Lo significativo del pasaje es que san Agustín, siguiendo a san Pablo, vincula el amor de Dios al hombre a la 
muerte de Cristo, mientras que en san Juan aparece vinculado previamente, en 1 Jn 4,9, a la encarnación (El amor de Dios hacia nosotros se ha manifestado en que Dios envió a su Hijo unigénito para que nosotros vivamos por él). El obispo de Hipona se separa de san Juan y sigue a san Pablo en el poner la manifestación suprema del amor de Dios al hombre en la pasión y muerte y no en la encarnación.

\section{e. Una teología del amor}

Mucho habla san Juan del amor en su primera Carta. San Agustín llega a afirmar que es casi su tema exclusivo, y en su comentario no se queda a la zaga. Pero mientras en san Juan se trata siempre del amor de Dios Padre, que encuentra su manifestación suprema en el envío de su Hijo al mundo (1 Jn 4,9), san Agustín, citando a Pablo, advierte esa manifestación en la muerte de Cristo, señalando tanto el amor del Padre (Rom 5,8; 8,32) como el de Cristo (Gál 2,20). Asimismo, tanto san Juan como san Agustín establecen una relación entre el amor y el Espíritu santo, pero esta relación es distinta.

La confianza de que habla san Juan en 1 Jn 3,22 (Tenemos confianza en Dios y todo lo que le pidamos lo recibiremos de él porque cumplimos sus mandamientos) lleva al predicador, de forma un tanto arbitraria, a citar, en IIEp 6,8, a Rom 8,26bc-27c (no sabemos qué pedir como conviene, pero el mismo Espíritu intercede por nosotros con gemidos inenarrables, puesto que él intercede por los santos). Luego se pregunta qué significa la afirmación de que el Espíritu intercede por los santos. En este caso no se trata propiamente de una pregunta que reclama una respuesta sino bien de una respuesta -la que el predicador quiere dar- que suscita la pregunta. Recurriendo a Rom 5,5b (La caridad de Dios derramada en nuestros corazones por medio del Espíritu santo que nos fue dado), responde que la que intercede es la caridad misma, donada al fiel cristiano por el Espíritu Santo. El santo ha vinculado Espíritu y amor, haciendo del primero el origen del segundo. Tal es la idea que le interesa resaltar, idea que él ha derivado de san Pablo.

Según san Juan, quien guarda su mandamiento permanecerá en Dios y Dios en él. $Y$ en esto conocemos que permanece en nosotros: por el Espíritu que nos ha dado (1 Jn 3,24). De tal afirmación, en IIEp 6,9 san Agustín concluye, en un primer momento, que evidentemente es fruto de la acción del Espíritu en el hombre que exista en él el amor y la caridad, aduciendo como prueba Rom 5,5b y, en un segundo momento, que quien posee la caridad, 
posee el Espíritu Santo. El predicador ha dado un paso que no se halla en san Juan. El apóstol se limita a indicar que el Espíritu testimonia -es decir, permite conocer- que Dios inhabita en el fiel que cumple sus mandatos (creer en Jesucristo y amar al hermano); para el santo, que deja de lado el primero de esos dos mandatos, afirmar que inhabita en Dios quien cumple el mandamiento del amor es lo mismo que afirmar que inhabita en Dios quien posee el Espíritu, porque poseer el Espíritu implica poseer el amor. Según él, guarda el mandamiento del amor quien posee el amor y posee el amor quien posee el Espíritu ${ }^{39}$. De ser testimonio de la inhabitación de Dios e indirectamente del amor, san Agustín ha convertido al Espíritu en fuente de ese amor fraterno. Lo mismo acontece en IIEp 8,12 a propósito de $1 \mathrm{Jn}$ 4,12-13 (Si nos amamos unos a otros, Dios permanece en nosotros y su amor ha llegado en nosotros a su plenitud. En esto conocemos que permanecemos en él y él en nosotros, en que nos ha dado de su Espíritu). También aquí la cuestión que formula revela la idea que quiere trasmitir: cómo conocer si se posee el Espíritu; su respuesta es que se posee el Espíritu si se posee el amor. Como prueba aduce, una vez más, Rom 5,5,b. El texto de san Juan le ha servido, de nuevo, para sostener que el amor tiene su fuente en el Espíritu Santo. El santo hace del Espíritu santo el revelador de la inhabitación de Dios en el fiel en cuanto donante del amor que la produce. Solo que san Juan se refiere a Dios Padre, no al Espíritu Santo. El mismo proceder y la misma respuesta encontramos en IIEp 6,10 en relación de nuevo con $1 \mathrm{Jn}$ 3,24 . Después de recordar, como objeción, que, según los Hechos de los Apóstoles, la prueba de haber recibido el Espíritu era el hablar lenguas (Hch 2,4$)$ y que en la actualidad la recepción del Espíritu en el bautismo no conlleva ese don, vuelve a preguntarse cómo se conoce ahora que se le posee. La respuesta es la de siempre: «Interrogue a su corazón. Si ama al hermano, el Espíritu de Dios permanece en él». Aunque en este caso acentúa más el aspecto eclesial -«Vea si mora en él el amor de la paz y de la unidad, el amor a la Iglesia difundida por todo el orbe de la tierra»- la respuesta es la misma, la prueba bíblica es la misma -Rom 5,5,b- y el presupuesto teológico es el mismo -el amor es don del Espíritu Santo-.

En el capítulo cuarto de su primera carta san Juan afirma que el amor es de Dios (1 Jn 4,7b) y que Dios es amor (1 Jn 4,8c). Para armonizar ambas

\footnotetext{
${ }^{39}$ Procede señalar que en la versión de 1 Jn 4,24 utilizada por IIEp el santo leía mandatum -en singular- no mandata -en plural-, según reza el texto original de la Carta y como aparece en s. 132 A [Mai 129],2).
} 
afirmaciones, en IIEp 7,6 san Agustín vincula el amor con el Espíritu. De una parte, el Espíritu es Dios, con lo que se da razón de 1 Jn 4,8c; por otra parte, el Espíritu es Dios de Dios, como proclama el Símbolo de la fe, con lo que se da razón de 1 Jn 4,7b. Es cierto que también el Hijo es Dios de Dios, pero la opción a favor del Espíritu viene confirmada, a entender del predicador, también aquí, por Rom 5,5b.

Resumiendo: al afirmar que Dios (Padre) es amor, san Juan pone en él la fuente del amor. La existencia de ese amor en el fiel cristiano es prueba de que Dios (Padre) inhabita en él, y el Espíritu recibido permite advertir esa inhabitación. San Agustín, en cambio, entiende que la afirmación de que Dios es amor hay que entenderla referida al Espíritu Santo porque ambos, el Espíritu y el amor son de Dios. Un presupuesto teológico -el Espíritu es Dios de Dios- asociado a un texto bíblico-Rom 5,5b-, le llevan a la conclusión de que el Espíritu es la fuente del amor. Que el amor es don del Espíritu es para él una verdad teológica que siempre tiene a mano para interpretar los textos juánicos en que aparecen relacionados el Espíritu y el amor o para resolver problemas que le pueden suscitar otros textos bíblicos. San Pablo se ha impuesto a san Juan. 